\title{
Factors Influencing Participation Of Healthy Volunteers In Clinical Trials: Findings From A Cross-Sectional Study In Delhi, North India
}

This article was published in the following Dove Press journal: Patient Preference and Adherence

Rajesh Ranjan ${ }^{1,2}$

Nidhi Bharal Agarwal'

Prem Kapur ${ }^{3}$

Amit Marwah'

Rizwana Parveen'

'Centre for Translational and Clinical Research, School of Chemical and Life Sciences, New Delhi I 10062, India;

${ }^{2}$ Department of Pharmaceutical Medicine, School of Pharmaceutical Education And Research, New Delhi I I0062, India; ${ }^{3}$ Department of Medicine, Hamdard Institute of Medical Sciences and Research, New Delhi I I0062, India

Correspondence: Nidhi Bharal Agarwal Centre for Translational and Clinical Research, School of Chemical and Life Sciences, Jamia Hamdard, New Delhi I 10062 , India

Tel +98 I8334770

Fax +9I-II- 26059663

Email nidhi.bharal@gmail.com
Purpose: To identify the specific motivations that drive healthy volunteers to consent for their participation in clinical studies. Additionally, the study aimed to document the sociodemographic determinants of participation in the trial related solely to the intention of securing financial gains.

Patients and methods: This cross-sectional study was conducted among subjects who participated as healthy volunteers in clinical trials conducted by Contract Research Organizations (CROs) of Delhi. Pre-tested, validated semi-structured questionnaires were used to collect baseline socio-demographic data, information about factors motivating participation in clinical trials, and pattern of utilisation of money received against participation in the trial. Logistic regression analysis was done to determine the factors that influenced participation in the trial related purely to the motive of securing financial gains.

Results: A total of 400 participants were selected. The majority of the volunteers $(77.5 \%)$ reported that their sole reason for participating in clinical trials was for monetary gain. Around a tenth of the volunteers participated with the intent to advance scientific knowledge and another $4.5 \%$ participated due to benefits of free medical check-ups. Participants in the age group of 29-38 years, those that were married, those residing in an urban slum, male participants, those with a high number of dependent family members (ie, 5 to 8), and those earning less than 5000 INR (71 USD) a month had higher odds of participating in a clinical trial purely for the financial benefits. Those educated till intermediate and above had lower odds of participation in the trial due to monetary benefits.

Conclusion: Our study shows that healthy volunteers in Delhi consider participation in clinical trials mainly because of the prospect of financial reward. More research is needed to inform judgments around the ethics of providing financial rewards and enrollment of healthy research volunteers.

Keywords: clinical trial, healthy volunteers, financial incentive, India

\section{Introduction}

Clinical research trials are critical to the advancement of medicine, especially for the discovery of new pharmaceutical entities, vaccines and medical devices. A typical clinical trial is an experiment that involves human participants in order to generate scientific knowledge that can subsequently be applied for the benefit of the society, at large. ${ }^{1}$ The product being investigated could be a drug molecule, vaccine, nutritional supplement or therapeutic or surgical procedure. ${ }^{1}$ The use of human subjects in these trials introduces specific challenges, particularly violations of ethical rights and health 
hazards. $^{2}$ Consequently, regulations have been developed to protect human rights and the dignity of individuals participating in biomedical research. ${ }^{3}$

Recently, increasing rates of participation of developing nations in multi-center clinical studies have been noticed. ${ }^{4}$ This increased participation could be because of reduced operational costs, ease of recruiting study subjects, ability to conduct research without stringent norms and improved regulatory capacity of these countries. ${ }^{4,5}$ As a general principle, the participation of an individual in a clinical trial should be based on a complete, transparent and satisfactory understanding of all aspects of the study along with informed consent to participate. In addition, it also depends upon the factors motivating a person to participate in the trial. This motivation to be involved with a clinical trial may vary from person to person. Prospective participants could be motivated by the intrinsic desire to help others or to advance the horizons of knowledge in medical science. ${ }^{6}$ Some could be attracted towards a better quality of care available as part of many clinical trials. ${ }^{6}$ However, amidst these underlying possible causes of motivation, there is also a growing concern that the basic principles of bioethics may be violated in developing countries. ${ }^{7}$ The characteristics of study populations from these low-resource settings, such as poverty, illiteracy, lack of education and limited availability/access to health care, may create inherent bias. ${ }^{8}$ The study subjects may not understand the study processes in detail or may participate in clinical studies because they do not have access to quality medical care. Studies have also noted that human subjects from these impoverished settings are more amenable to participation in the clinical trial because of the expectation of financial benefits. ${ }^{9-11}$

While clinical research participants who suffer from diseases are often keen to participate in research with the hope of gaining possible therapeutic benefits and free medical treatment, or to help better understand the disease that afflicts them, the motivations of healthy participants are likely to be quite different. ${ }^{12,13}$ Healthy volunteers for clinical trials are important for bioequivalence studies that involve the development of new drugs, testing new formulations as well as investigating drug safety, dosing, and pharmacokinetics. ${ }^{14,15}$ Recent years have observed increasing importance of bioequivalence studies due to a surge in the production and consumption of pharmaceutical products. There is a substantial lack of studies that examine the reasons why healthy individuals volunteer to participate in research. Only a few studies report the motivations of healthy volunteers in clinical research trials. ${ }^{10,11,16-18}$ The widespread notion is that healthy volunteers who enroll in clinical research are motivated strictly by financial incentives. ${ }^{19,20}$ Financial incentives offer a peculiar ethical dilemma, that too in a low-income setting. There is a growing concern that volunteers who are only motivated by monetary gains often disregard health risks or may not be able to properly assess the risk in a particular study. ${ }^{21}$ There is also a concern that payment for research participation disproportionally attracts low-income volunteers and thus results in research that may lack external validity. ${ }^{21}$ With these considerations, the current study was done with the primary objective of identifying the specific motivators that prompt healthy volunteers to participate in clinical studies and to elucidate the sociodemographic factors that determine participation in the trial solely with the intention of securing financial gains.

\section{Materials And Methods Study Design And Participants}

This cross-sectional study was conducted among subjects who participated as "healthy volunteers" in clinical trials conducted by Contract research Organizations (CROs) of Delhi. These CROs usually conduct bioavailability and bioequivalence studies. A volunteer-providing agency based in Delhi that provided volunteers to these contract research organizations was contacted. A list of all healthy volunteers who previously participated in one or more clinical trials was made and participants for this study were selected randomly from this list. Volunteers in the age group of 18-55 years who had participated in at least one clinical trial and who consented to participate in the current study were included. Institutional ethics committee approval from Jamia Hamdard University was sought before the study was started (Ethics approval number $\mathrm{XX}$ ). Written informed consents were obtained from the participants. Data were collected over a time period of 1 year, from April 2016 to March 2017.

\section{Sampling Technique And Sample Size}

The list of volunteers was procured from volunteer-providing consultancy. The list consisted of about 1010 male volunteers and 125 female volunteers. Participants for this study were selected randomly, using a random number table. A total of 400 participants were selected out of which 356 were males $(356 / 1010=35.2 \%)$ and 44 were females $(44 / 125=35.2 \%)$. We ensured that there is a similar representation of both sexes in terms of proportion 
drawn from the list of participants. We used the formula $4 p$ $(1-p) / d^{2}$ to calculate the required sample size where $p=$ expected prevalence or proportion (we assumed the prevalence of participation "solely" because of financial gains to be $50 \%$ as there are no data available from Indian context on this issue); $d=$ absolute precision of $5 \%$. The total sample size came out to be 400 .

\section{Tools Used For Data Collection And Data Collection Procedure}

Pre-tested, validated semi-structured questionnaires were used to collect baseline socio-demographic data; information about factors motivating participation in clinical trials and pattern of utilisation of money received against participation in the trial. The data were collected at the study office by trained study investigators through face-to-face interactions. We conducted three focus group discussions (FGDs) to understand the motivation behind their participation in previous clinical trials. Each FGD consisted of 6 to 8 participants. These FGDs were conducted by trained study investigators with assistance from additional personnel involved in the study. A detailed list of questions to be discussed was prepared in advance of conducting the FGDs.

\section{Data Analysis}

The data were analyzed using the software "Statistical Package for Social Science" (SPSS) version 21.0. Distribution of data was examined. Descriptive statistics were used and results were expressed as percentages as the data were categorical in nature. The primary outcome of the analyses was to identify specific motivators that prompt healthy volunteers to participate in clinical studies and to identify factors that determine participation in the trial solely with the intention of securing financial gains. In order to identify specific motivators for participation in clinical studies, we adopted two data collection strategies. Firstly, we conducted focus group discussions (FGDs). Data from FGDs were analysed using a thematic analysis. Data were analyzed in the local language so the researcher stayed as close to the participant's verbatim as possible. Each discussion was recorded with prior written informed consent. These discussions were expanded and transcribed. The transcriptions were reviewed and read carefully to understand and identify the emerging themes. Excerpts from the original transcripts were included in the analysis. Secondly, we used a semi-structured questionnaire to document the reported reasons for participation in the trial. These responses were coded and entered in the database for analyses. We calculated the proportion of study subjects that reported a particular reason.

We performed logistic regression to determine the factors that influenced participation in the trial purely with the motive of securing financial gains. The outcome was coded as " 0 " for those who did not participate mainly because of financial gains and "1" for those who had financial gains as the only motive to participate. Potential variables were put in the univariate model and their corresponding p-value was recorded. All those variables for which the p-value was less than 0.20 were taken forward for the multivariable regression analysis. We used a stepwise backward method for multivariable regression and reported associations using the odds ratio with $95 \%$ confidence intervals. A p-value of $<0.05$ was considered for statistical significance.

\section{Results}

\section{Socio-Demographic Details Of The Study Participants}

Table 1 presents the socio-demographic details of the study participants. The majority $(89.0 \%)$ were males, in the age group of 18 to 28 years $(60.0 \%)$, residing with 5 to 8 dependent family members $(72.5 \%)$, married $(74 \%)$ and living in a joint family (67.0\%). Most of them were educated till middle school (49.8\%) and $6.2 \%$ were illiterate. More than a half $(59.8 \%)$ were earning less than 5000 rupees per month (71 USD/month) and a similar proportion of the volunteers were residing in urban non-slum areas of Delhi. The majority of volunteers $(56.5 \%)$ had participated in 1 to 3 clinical trials. Around two-fifth (38\%) volunteers participated in 4 to 6 clinical trials. The remaining participants were involved in 7 to $9(3.0 \%)$ and $\geq 10(2.5 \%)$ clinical trials, respectively.

\section{Motives Driving Participation In A Clinical Trial}

The majority of the volunteers $(77.5 \%)$ reported that their sole intent to participate in clinical trials was for monetary gain (Table 2). Around a tenth of the volunteers participated in clinical trials with the intent to advance scientific knowledge and considered such an act as a social cause. Another reason reported was the benefits of free medical check-ups (4.5\%). A total of $5.0 \%$ of volunteers reportedly participated with the intent of getting free medical checkups as well as the financial benefits (Table 2). 
Table I Socio-Demographic Characteristics Of Study Participants $(\mathrm{N}=400)$

\begin{tabular}{|c|c|c|}
\hline \multirow[t]{2}{*}{ Socio-Demographic Variables } & \multicolumn{2}{|c|}{$N=400$} \\
\hline & $\mathbf{n}$ & $\%$ \\
\hline \multicolumn{3}{|l|}{ State of Origin } \\
\hline Delhi & 298 & 74.5 \\
\hline Outside Delhi & 102 & 25.5 \\
\hline \multicolumn{3}{|l|}{ Age group (yrs) } \\
\hline $18-28$ & 240 & 60.0 \\
\hline $29-38$ & 146 & 36.5 \\
\hline$>38$ & 14 & 3.5 \\
\hline \multicolumn{3}{|l|}{ Marital status } \\
\hline Married & 296 & 74.0 \\
\hline Unmarried & 104 & 26.0 \\
\hline \multicolumn{3}{|l|}{ Educational qualification } \\
\hline Illiterate & 25 & 6.2 \\
\hline Middle school completed & 199 & 49.8 \\
\hline High school completed & 104 & 26.0 \\
\hline Intermediate and above & 72 & 18.0 \\
\hline \multicolumn{3}{|l|}{ Current residence } \\
\hline Urban slum & 166 & 41.5 \\
\hline Urban non-slum & 200 & 50.0 \\
\hline Rural & 34 & 8.5 \\
\hline \multicolumn{3}{|l|}{ Religion } \\
\hline Hindu & 304 & 76.0 \\
\hline Muslim & 90 & 22.5 \\
\hline Others (Sikh and Christian) & 6 & 1.5 \\
\hline \multicolumn{3}{|l|}{ Sex } \\
\hline Male & 356 & 89.0 \\
\hline Female & 44 & 11.0 \\
\hline \multicolumn{3}{|l|}{ Dependent Family Members } \\
\hline$<4$ Members & 96 & 24.0 \\
\hline 5-8 Members & 290 & 72.5 \\
\hline$>8$ Members & 14 & 3.5 \\
\hline \multicolumn{3}{|l|}{ Type of family } \\
\hline Nuclear family & 132 & 33.0 \\
\hline Joint family & 268 & 67.0 \\
\hline \multicolumn{3}{|l|}{ Monthly income (Rs) } \\
\hline$\leq 5000(\leq 7 \mid$ USD $)$ & 239 & 59.8 \\
\hline $500 \mid$ to 10,000 (>7| to I43 USD) & 56 & 14.0 \\
\hline$>10000(>143$ USD $)$ & 105 & 26.2 \\
\hline \multicolumn{3}{|l|}{ Occupation } \\
\hline Unemployed & 18 & 4.5 \\
\hline Un-skilled worker & 272 & 68.0 \\
\hline Semi-skilled worker & 62 & 15.5 \\
\hline Skilled worker & 28 & 7.0 \\
\hline Clerical, shop/farm-owner, etc. & 12 & 3.5 \\
\hline Semi-professional & 4 & 1.0 \\
\hline Professional & 4 & 1.0 \\
\hline
\end{tabular}

\section{Factors Influencing Participation In A Trial} Solely For Financial Gains

We explored factors that influenced participation in clinical trials "solely" for financial benefits. In the multivariable model, after adjusting for all potential confounders, we found that participants in the age group of 29-38 years [OR 2.98; 95\% CI: 1.63-5.45], those that were married [OR 2.21; 95\% CI: 1.28-3.61], those residing in urban slum [OR 2.98; 95\% CI: 1.22-6.81], male participants [OR 2.92; 95\% CI: 1.37-5.68], those with high number of dependent family members (ie 5 to 8 ) [OR 4.12 ; $95 \%$ CI: 2.29-8.03] and those earning less than 5000 INR (71 USD) a month [OR 3.19; 95\% CI: 1.94-6.04] had higher odds of participating in a clinical trial purely for the financial benefits (Table 3). Further, compared to those who had participated in 1 to 3 trials previously, those who had participated in 4 or more trials had higher odds of participation for financial gains [OR 2.23; 95\% CI: 1.37-3.98]. It is worth noting that compared to those who were illiterate, those educated till intermediate and above had lower odds of participation [OR 0.37 ; $95 \% \mathrm{CI}$ : $0.16-0.97]$ in the trial due to monetary benefits.

\section{Pattern Of Utilization Of The Money Received For Participation In The Trial}

All the respondents reported receiving financial incentives for their participation in the trial. The majority of the volunteers $(52.0 \%)$ reportedly spent the money received predominantly in fulfilling the basic needs of their family such as food, house rent and education of their children (Figure 1). Around a fifth (27\%) used the money as savings for their future. Thirty-two (8\%) volunteers spent the money mostly on health care and the remaining $13 \%$ reported that they spent most of the money received for the consumption of alcohol and other substances meant for abuse (Figure 1).

\section{Findings Of The Qualitative Interviews}

A total of 3 focus group discussions (FGDs) were done with the study participants. Each FGD consisted of 6 to 8 participants. These discussions were centered on understanding the prime motive that drives participation in clinical trials. Financial incentives emerged as one of the important considerations along with the availability of free health care check-ups during the time of participation in the trial. 
Table 2 Self-Reported Motives Behind Participation Of Volunteers In Clinical Trials ( $N=400)$

\begin{tabular}{|l|l|l|}
\hline Reason(s) Reported & Total No. Of Respondents (N) \\
\hline Only for financial gain & 310 & $\%$ \\
In the interest of advancing science and benefit of the society & 36 & 77.5 \\
Only for free medical check-up & 18 & 9.0 \\
Both for free medical check-up and financial gain & 20 & 4.5 \\
Both social cause and for financial gain & 12 & 5.0 \\
Both the social cause and for free medical check-up & 4 & 3.0 \\
\hline
\end{tabular}

"I have participated in clinical trials mainly because they pay well and at the same time, they do health checkups for free and I get to know how my health is." [Male; 28 years; had participated in 2 trials]

I have a big family and I am the only earning member. I have many responsibilities at home and participating in these studies provides me some additional income. Although, it might sound unreasonable but money is the key attraction for me. [Male; 34 years; had participated in 5 trials]

Some participated only with the expectation to have free medical services as part of the study.

I was getting regular medical check-ups so I was quite happy with that. I could not have afforded the health care otherwise. [Female; 29 years; participated in 2 trials]

There were some participants that said that their motivation to participate in the trial was to help advance scientific knowledge and help others.

I participated with the idea that my involvement in studies could help getting answers to health related issues. If not many people participate, nobody's is going to know the answers. [Female; 31 years; participated in one trial]

\section{Discussion}

Because of its large population and growing capacities for biomedical research, India is increasingly recognized as a potential site for health research. ${ }^{22,23}$ Enrollment and sustained participation are undoubtedly the most important phases of a clinical trial. ${ }^{24,25}$ It is important to identify the reasons driving participation in clinical studies in order to ensure that the clinical trial does not suffer from high dropouts, and the results emerging from the trial have robust validity. Our study identified factors facilitating trial participation among apparently healthy subjects. Such insights into the mindsets of subjects in relation to trial participation can guide investigators and sponsors when they plan trials in the future. Non-consideration of these factors during the planning stage may lead to delays in the trial enrolment and subsequent implications on trial completion and costs.

Previous studies have highlighted a wide array of factors that determine this willingness to participate such as education, age of the participant, participant preference for a certain treatment, and a multitude of other reasons. ${ }^{9,24-28}$ Apart from these, there are other factors that cannot be generalized to individuals from varied cultures with divergent lifestyles, socio-economic environments and religious beliefs. This is especially applicable in large culturally diverse settings such as India. ${ }^{29}$ Another important aspect to note is that individuals who suffer from any ailment often put forward their desire to participate in a trial with the expectation of securing free medical care or therapeutic benefits from the drug under investigation; however, we do not fully understand the underlying motivations of healthy participants. $^{12,13,29}$ In the present study, we aimed to identify motivators that prompt "healthy" volunteers to participate in clinical studies. We also attempted to document factors that determine participation in the trial "solely" with the intention of securing financial gains. As an additional objective, we also aimed to assess the pattern of utilization of money received against the participation in a trial.

We found that the majority of the volunteers $(\sim 78 \%)$ reported that their sole intent to participate in clinical trials was for monetary gains. Similar findings underlying financial motives as the prominent reason to participate in clinical trials have been reported by previous studies as well. $^{9,10,25,30,31}$ For instance, in a survey conducted by Walsh et al, "non-volunteers" for a clinical trial were less likely to report financial motivations as a reason to participate in research than those who volunteered $(52 \%$ vs $81 \%$, respectively). ${ }^{30}$ This probably suggests that for prospective volunteers, financial gains could be an important factor determining their willingness to take part in a trial. A study from Indonesia showed that financial motivation 
Table 3 Factors Associated With Participation In Clinical Trials Solely With The Intent Of Securing Financial Gains (N=400)

\begin{tabular}{|c|c|c|c|}
\hline \multirow[t]{2}{*}{ Participation For Financial Benefits } & \multirow[t]{2}{*}{ Proportion (\%) } & \multirow{2}{*}{$\begin{array}{l}\text { Univariate } \\
\text { OR }(95 \% \mathrm{CI})\end{array}$} & \multirow{2}{*}{$\begin{array}{l}\text { Multivariate } \\
\text { OR (95\% CI) }\end{array}$} \\
\hline & & & \\
\hline \multicolumn{4}{|l|}{ Age group (in years) } \\
\hline $18-28$ & $170 / 240(70.8)$ & Ref & Ref \\
\hline $29-38$ & $130 / 146(89.0)$ & $3.34(1.81-6.45)^{*}$ & $2.98(1.63-5.45)^{*}$ \\
\hline$>38$ & $10 / 14(71.4)$ & $1.03(0.28-4.64)$ & $0.93(0.25-4.49)$ \\
\hline \multicolumn{4}{|l|}{ Marital status } \\
\hline Unmarried & $68 / 104(65.4)$ & Ref & Ref \\
\hline Married & $242 / 296(81.7)$ & $2.37(1.39-4.02)^{*}$ & $2.21(1.28-3.6 I)^{*}$ \\
\hline \multicolumn{4}{|l|}{ Educational status } \\
\hline Illiterate & 18/25 (72.0) & Ref & Ref \\
\hline Middle school completed & $172 / 199(86.4)$ & $2.47(0.79-6.94)$ & $2.23(0.52-6.18)$ \\
\hline High school completed & $87 / 104(83.6)$ & $1.99(0.60-5.98)$ & $1.87(0.49-5.12)$ \\
\hline Intermediate and above & $33 / 72(45.8)$ & $0.33(0.10-0.96) *$ & $0.37(0.16-0.97)^{*}$ \\
\hline \multicolumn{4}{|l|}{ State of origin } \\
\hline Delhi & $228 / 298(76.5)$ & Ref & Ref \\
\hline Outside Delhi & $82 / 102(80.4)$ & $1.26(0.70-2.32)$ & $1.18(0.67-2.19)$ \\
\hline \multicolumn{4}{|l|}{ Place of residence } \\
\hline Rural & $20 / 34(58.8)$ & Ref & Ref \\
\hline Urban slum & $135 / 166(81.3)$ & $3.05(1.27-7.13) *$ & $2.98(\mid .22-6.8 I)^{*}$ \\
\hline Urban non-slum & $155 / 200(77.5)$ & $2.4 \mathrm{I}(1.03-5.47) *$ & $2.13(0.79-4.75)$ \\
\hline \multicolumn{4}{|l|}{ Religion } \\
\hline Hindu & $236 / 304(77.6)$ & Ref & Ref \\
\hline Muslim & $72 / 90(80.0)$ & $1.15(0.63-2.19)$ & $1.12(0.64-1.87)$ \\
\hline Others & $2 / 6(33.3)$ & $0.14(0.03-1.04)$ & $0.23(0.07-1.16)$ \\
\hline \multicolumn{4}{|l|}{ Sex of the participant } \\
\hline Female & $25 / 44(56.8)$ & Ref & Ref \\
\hline Male & $285 / 356(80.1)$ & $3.05(1.49-6.12) *$ & $2.92(1.37-5.68)^{*}$ \\
\hline \multicolumn{4}{|l|}{ Type of family } \\
\hline Nuclear & $100 / 132(75.8)$ & Ref & Ref \\
\hline Joint & $210 / 268(78.4)$ & $1.16(0.68-1.94)$ & $1.08(0.64-1.78)$ \\
\hline \multicolumn{4}{|l|}{ Number of dependent family members } \\
\hline$\leq 4$ & $52 / 96(54.2)$ & Ref & Ref \\
\hline 5 to 8 & $248 / 290(85.5)$ & $4.90(2.87-8.65) *$ & $4.12(2.29-8.03)^{*}$ \\
\hline$>8$ & $10 / 14(71.4)$ & $2.11(0.56-9.82)$ & $1.93(0.52-9.22)$ \\
\hline \multicolumn{4}{|l|}{ Monthly income (in INR) } \\
\hline$>10,000(>143$ USD $)$ & $67 / 105(63.8)$ & Ref & Ref \\
\hline$>5000$ to 10,000 (>7I to I43 USD) & $35 / 56(62.5)$ & $0.95(0.46-1.96)$ & $0.87(0.44-1.83)$ \\
\hline$\leq 5000(\leq 7 \mid$ USD) & $208 / 239(87.0)$ & $3.81(2.12-6.84) *$ & $3.19(1.94-6.04)^{*}$ \\
\hline \multicolumn{4}{|l|}{ Number of trials previously participated in } \\
\hline $\mathrm{I}-3$ & $160 / 226(70.8)$ & Ref & Ref \\
\hline$\geq 4$ & $150 / 174(86.2)$ & $2.57(1.49-4.52) *$ & $2.23(1.37-3.98)^{*}$ \\
\hline
\end{tabular}

Note: *Statistical significance at $\mathrm{p}$-value $<0.05$.

could increase the number of individuals willing to participate in a vaccine trial. ${ }^{25} \mathrm{~A}$ fairly recent meta-analysis aimed to document the factors leading to participation in clinical trials in Indian context reported that willingness to participate was more pronounced in the presence of monetary remuneration and the respondents expected an 


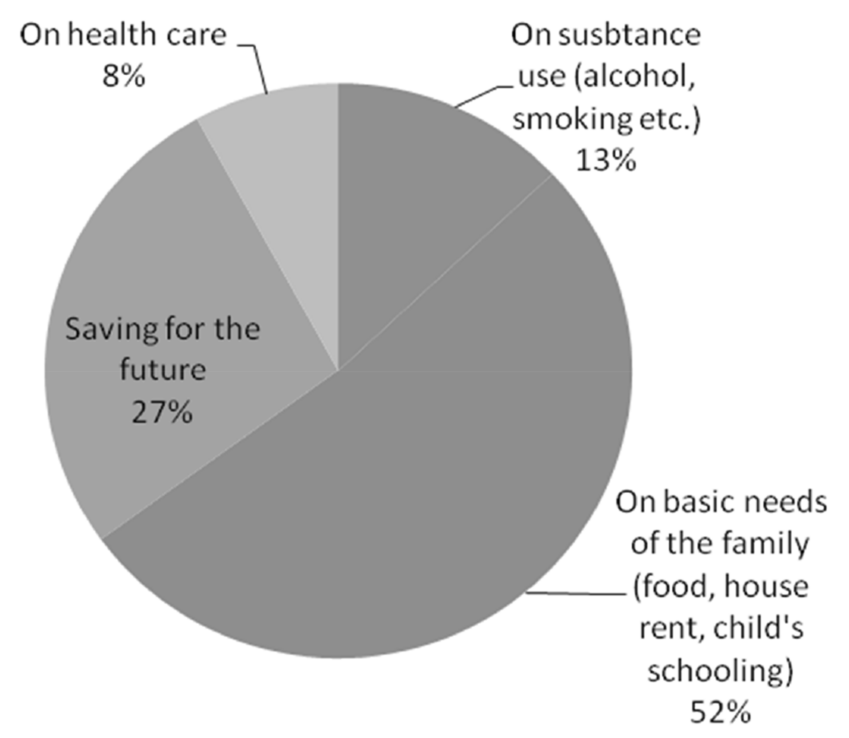

Figure I Utilization pattern of money received for participation in the clinical trial $(N=400)$.

incentive for clinical trial participation either in terms of monetary gains or incentives. ${ }^{29}$

In our study, we also found that a tenth of the participants got involved in the trial because of underlying altruism. This proportion is much less than that reported from developed settings. Berg et al (2010) assessed the attitudes of participants towards pharmacokinetic (phase I) studies in the United States. ${ }^{32}$ The majority of the subjects (72\%) identified altruistic reasons for participation. This difference in the underlying motivation to participate in a trial among low-resource settings and developed settings does not come as a surprise. In a developing country like India where poverty is widespread, participating in clinical trials that offer monetary incentives is seen as a viable additional source of income. Even when the trial does not offer financial compensation, free care and medical treatment proves to be a compelling reason for individuals who otherwise fail to afford the cost of treatment. ${ }^{29}$

Through logistic regression, we identified certain factors that were strongly associated with the decision to participate in the trial purely for financial gains. We found that increased age, being married, residing in an urban slum, male sex, having a high number of dependent family members and monthly earning of less than 5000 INR led to higher odds of participating in a clinical trial purely for the financial benefit. On the contrary, being educated lowered the odds of participation due to monetary benefits. The findings seem pragmatic and plausible as the factors associated with increased odds of participation due to monetary gains are also the factors that are an indirect proxy for low socio-economic status and increased familial responsibilities. It is striking to note that those who had participated in an increasing number of trials were more likely to participate because of only financial gains. We also found that around four-fifths of the participants used the money received in return for their participation in a trial for fulfilling the basic needs of the family and savings for future. This highlights that even though the intent of financial gains may predominate their reason to participate, yet the money accrued is brought to use in a reasonably accepted manner. It was, however, concerning that around $13 \%$ of the participants used the money to procure substances meant to be abused such as alcohol and/or tobacco. Stringent mechanisms should be instituted to ensure that the financial gains received during participation in trials should not be utilized in a manner that is harmful for health. Other option could be to restrict giving cash but instead provide benefits in forms such as health care vouchers, educational assistance for their children etc.

\section{Strengths And Limitations Of The Study}

There are a limited number of studies that focus on understanding the specific attitudes and willingness of healthy volunteers, particularly within the Indian population, to participate in a clinical trial. This is probably one of the few such studies. Our study population comprised of individuals who had earlier participated in clinical trials and therefore the data generated from this study are backed by their previous experiences and present the current scenario. One of the major limitations of this study is the relatively small sample size and from within a specified region of the country, ie Delhi, which curtails the external validity of the findings. Another limitation is the use of self-reported information. We used pretested semi-structured questionnaires for collecting data from the participants. Lack of reliable methods to verify the information provided could lead to potential reporting bias in this study.

One major limitation that we acknowledge is the bias in the selection of participants, as those registered with a "volunteer recruitment agency" were more likely to be registered for the purpose of remuneration. Hence, the generalizability of the universe of healthy volunteers was limited. Further, the volunteer recruitment agency that we contacted for the study provided participants largely for $\mathrm{BA} / \mathrm{BE}$ studies, and these studies are known to compensate participants. However, vaccine studies and other phase 1 studies also require healthy participants but do 
not compensate on the same scale. Therefore, our study sample was not largely representative, and therefore, the external validity of the findings is limited.

\section{Conclusions}

Our study shows that healthy volunteers in Delhi consider participation in clinical trials mainly because of the prospect of financial reward. Being of male sex, married, having low income and a higher number of dependent family members are the key factors that are associated with the intent to participate solely based on expectations of monetary gains. Our study highlights a clear need for more research to inform judgments around the ethics of providing financial rewards and enrollment of healthy research volunteers.

\section{Ethical Approval}

In accordance with the Committee on Publication Ethics (COPE) requirements, we acknowledge that human subjects research was approved by the Institutional Review Board (IRB) at Jamia Hamdard University, New Delhi (JM\#1298/ 2024A).

\section{Data Availability}

Requests for data used in the preparation of the manuscript can be directed to the corresponding author.

\section{Author Contributions}

All authors contributed to data analysis, drafting or revising the article, gave final approval of the version to be published, and agree to be accountable for all aspects of the work.

\section{Disclosure}

The authors report no conflicts of interest in this work.

\section{References}

1. Umscheid CA, Margolis DJ, Grossman CE. Key concepts of clinical trials: a narrative review. Postgrad Med. 2011;123(5):194-204. doi:10.3810/pgm.2011.09.2475

2. Yip C, Han NLR, Leong Sng B. Legal and ethical issues in research. Indian J Anaesth. 2016;60(9):684-688. doi:10.4103/0019-5049.190627

3. World Medical Association. World Medical Association Declaration of Helsinki: ethical principles for medical research involving human subjects. JAMA. 2013;310:2191-2194.

4. Grover $\mathrm{S}, \mathrm{Xu} \mathrm{M}$, Jhingran A, et al. Clinical trials in low and middleincome countries - successes and challenges. Gynecol Oncol Rep. 2016;19:5-9. doi:10.1016/j.gore.2016.11.007

5. Devasenapathy N, Singh K, Prabhakaran D. Conduct of clinical trials in developing countries: a perspective. Curr Opin Cardiol. 2009;24 (4):295-300.
6. Gaul C, Schmidt T, Helm J, Hoyer H, Haerting J. Motivation and barriers to participation in clinical trials. Med Klin (Munich). 2006;101(11):873-879. doi:10.1007/s00063-006-1116-7

7. Weigmann K. The ethics of global clinical trials. EMBO Rep. 2015;16(5):566-570. doi:10.15252/embr.201540398

8. Emanuel EJ, Wendler D, Killen J, Grady C. What makes clinical research in developing countries ethical? The benchmarks of ethical research. $J$ Infect Dis. 2004;189(5):930-937. doi:10.1086/jid.2004.189.issue-5

9. Almeida L, Azevedo B, Nunes T, Vaz-da-silva M, Soares-da-silva P. Why healthy subjects volunteer for phase I studies and how they perceive their participation? Eur J Clin Pharmacol. 2007;63 (11):1085-1094. doi:10.1007/s00228-007-0368-3

10. Kass NE, Myers R, Fuchs EJ, Carson KA, Flexner C. Balancing justice and autonomy in clinical research with healthy volunteers. Clin Pharmacol Ther. 2007;82(2):219-227. doi:10.1038/sj.clpt.6100192

11. van Gelderen CE, Savelkoul TJ, van Dokkum W, Meulenbelt J. Motives and perception of healthy volunteers who participate in experiments. Eur J Clin Pharmacol. 1993;45(1):15-21. doi:10.1007/BF00315344

12. Madsen SM, Mirza MR, Holm S, Hilsted KL, Kampmann K, Riis P. Attitudes towards clinical research amongst participants and nonparticipants. J Intern Med. 2002;251(2):156-168. doi:10.1046/j.13652796.2002.00949.x

13. Agrawal M, Grady C, Fairclough DL, Meropol NJ, Maynard K, Emanuel EJ. Patients' decision-making process regarding participation in phase I oncology research. J Clin Oncol. 2006;24(27):44794484. doi:10.1200/JCO.2006.06.0269

14. Vetchý D, Frýbortová K, Rabisková M, Daneckova H. Bioequivalence studies of pharmaceutical preparations. Cas Lek Cesk. 2007;146(5):431-433.

15. Galgatte Upendra C. Study on requirements of bioequivalence for registration of pharmaceutical products in India, South-Africa and Australia. Am J PharmTech Res. 2013;3(1):289-305.

16. Novak E, Seckman CE, Stewart RD. Motivations for volunteering as research subjects. J Clin Pharmacol. 1977;17(7):365-371. doi:10.1002/jcph.1977.17.issue-7

17. Vrhovac R, Francetic I, Rotim K. Drug trials on healthy volunteers in Yugoslavia. Int J Clin Pharmacol Ther Toxicol. 1990;28(9):375-379.

18. Tishler CL, Bartholomae S. Repeat participation among normal healthy research volunteers: professional guinea pigs in clinical trials? Perspect Biol Med. 2003;46(4):508-520. doi:10.1353/pbm.2003.0094

19. Lemmens T, Elliott C. Guinea pigs on the payroll: the ethics of paying research subjects. Account Res. 1999;7(1):3-20. doi:10.1080/08989 629908573939

20. Tishler CL, Bartholomae S. The recruitment of normal healthy volunteers: a review of the literature on the use of financial incentives. $J$ Clin Pharmacol. 2002;42(4):365-375. doi:10.1177/00912700222011409

21. Stunkel L, Grady C. More than the money: a review of the literature examining healthy volunteer motivations. Contemp Clin Trials. 2011;32(3):342-352. doi:10.1016/j.cct.2010.12.003

22. Joseph J. Entering the contract research industry in India. Contem Clin Trials. 2008;29:311-313. doi:10.1016/j.cct.2007.10.006

23. Gupta YK, Padhy BM. India's growing participation in global clinical trials. Trends Pharmacol Sci. 2011;32(6):327-329. doi:10.1016/j. tips.2011.02.017

24. Harapan H, Anwar S, Bustaman A, et al. Community willingness to participate in a dengue study in Aceh Province, Indonesia. PLoS ONE. 2016;11(7):e0159139. Published 2016 Jul 12. doi:10.1371/ journal.pone. 0159139

25. Harapan H, Mudatsir M, Yufika A, et al. Willingness to participate and associated factors in a zika vaccine trial in Indonesia: a crosssectional study. Viruses. 2018;10(11):648. Published 2018 Nov 18. doi:10.3390/v10110648

26. Gitanjali B, Raveendran R, Pandian DG, Sujindra S. Recruitment of subjects for clinical trials after informed consent: does gender and educational status make a difference? $J$ Postgrad Med. 2003;49:109-113. 
27. Catania C, De Pas T, Goldhirsch A, et al. Participation in clinical trials as viewed by the patient: understanding cultural and emotional aspects which influence choice. Oncology. 2008;74:177-187. doi:10.1159/000151365

28. Unson CG, Ohannessian C, Kenyon L, Case A, Reisine S, Prestwood $\mathrm{K}$. Barriers to eligibility and enrollment among older women in a clinical trial on osteoporosis: effects of ethnicity and SES. J Aging Health. 2004;16:426-443. doi:10.1177/0898264304264211

29. Shah JY, Phadtare A, Rajgor D, et al. What leads Indians to participate in clinical trials? A meta-analysis of qualitative studies. PLoS ONE. 2010;5(5):e10730. doi:10.1371/journal.pone.0010730
30. Walsh JA, Nash MM. Personality characteristics of volunteers for medical research. Crim Justice Behav. 1978;5(2):99-116. doi:10.1177/009385487800500201

31. Nappo SA, Iafrate GB, Sanchez ZM. Motives for participating in a clinical research trial: a pilot study in Brazil. BMC Public Health. 2013;13:19. doi:10.1186/1471-2458-13-19

32. Berg SL, Winick N, Ingle AM, Adamson PC, Blaney SC. Reasons for participation in optional pharmacokinetic studies in children with cancer: a Children's Oncology Group phase 1 consortium study. Pediatr Blood Cancer. 2010;55(1):119-122. doi:10.1002/pbc.22529

\section{Publish your work in this journal}

Patient Preference and Adherence is an international, peer-reviewed, open access journal that focusing on the growing importance of patient preference and adherence throughout the therapeutic continuum. Patient satisfaction, acceptability, quality of life, compliance, persistence and their role in developing new therapeutic modalities and compounds to optimize clinical outcomes for existing disease states are major areas of interest for the journal. This journal has been accepted for indexing on PubMed Central. The manuscript management system is completely online and includes a very quick and fair peer-review system, which is all easy to use. Visit http:// www.dovepress.com/testimonials.php to read real quotes from published authors. 